\title{
PETROGRAFIA, QUÍMICA MINERAL E GEOTERMOBAROMETRIA DE METAPELITO DO GRUPO CARRANCAS NA NAPPE DE LUMINÁRIAS (MG)
}

\author{
PETROGRAPHY, MINERAL CHEMISTRY AND THERMOBAROMETRY OF METAPELITE OF \\ THE CARRANCAS GROUP IN THE LUMINÁRIAS NAPPE - MINAS GERAIS - BRAZIL
}

\author{
Regiane Andrade FUMES ${ }^{1}$, George Luiz LUVIZOTTO², Renato MORAES ${ }^{3}$, Edson \\ Ricardo Maia FERRAZ ${ }^{1}$ \\ ${ }^{1}$ Universidade Estadual Paulista (Unesp), Instituto de Geociências e Ciências Exatas, Rio Claro, São Paulo, Brasil -Programa de Pós- \\ Graduação em Geociências e Meio Ambiente. Email: regianefumes@gmail.com; ercmaia@gmail.com. \\ ${ }^{2}$ Universidade Estadual Paulista (Unesp), Instituto de Geociências e Ciências Exatas, Rio Claro - SP, Brasil. Email: \\ georgell@rc.unesp.br. \\ ${ }^{3}$ Universidade de São Paulo. Instituto de Geociências, São Paulo - SP, Brasil. Email: rmoraes@usp.br

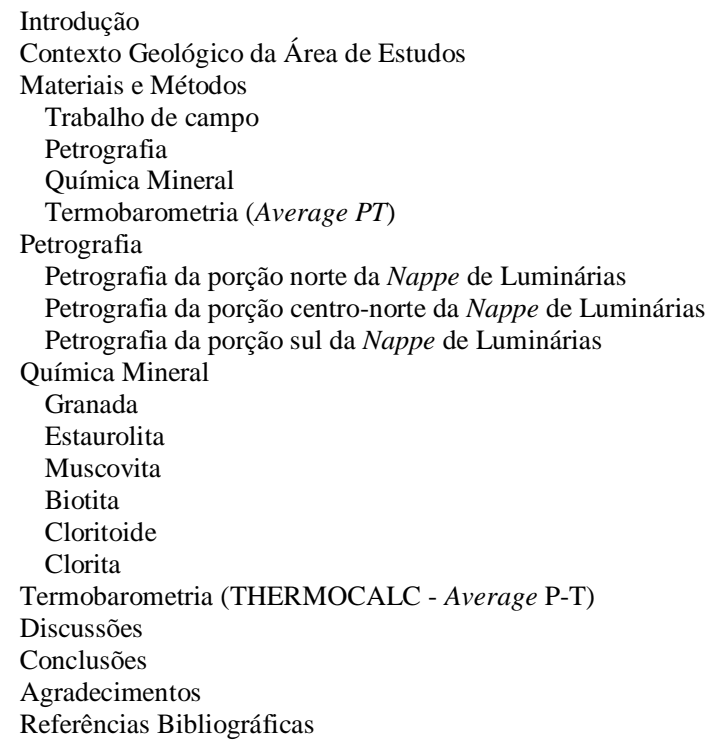

RESUMO - A Nappe Luminárias corresponde à estrutura alongada de orientação NNE-SSW, situada na porção sul do Orógeno Brasília, de idade neoproterozoica, na borda sul do Cráton do São Francisco. Tal estrutura é composta por metapelitos e quartzitos do Grupo Carrancas. O presente trabalho foca na caracterização metamórfica das suas rochas e utiliza petrografia, química mineral e geotermobarometria. A paragênese observada na porção norte é $\mathrm{Chl}+\mathrm{St}+\mathrm{Ky}+\mathrm{Rt}+\mathrm{Qtz}+\mathrm{Ms}$; na porção centro norte é $\mathrm{St}+\mathrm{Grt}+\mathrm{Bt}+\mathrm{Rt}+\mathrm{Qtz}+\mathrm{Ms}$ e na porção sul é $\mathrm{Grt}+\mathrm{Ky}+\mathrm{St}+\mathrm{Rt}+\mathrm{Qtz}+\mathrm{Ms}$. Clorita retrometamórfica é observada no centro-norte e sul e biotita retrometamórfica é observada no sul. As condições do pico metamórfico obtidas pelo método average PT do THERMOCALC na porção centro-norte são de $570 \pm 67{ }^{\circ} \mathrm{C}$ e $9,4 \pm 1,9$ kbar e na porção sul $609 \pm 63{ }^{\circ} \mathrm{C}$ e $11,4 \pm 3,9$ kbar. Os resultados indicam a presença de gradiente metamórfico com condições que variam de fácies anfibolito inferior na porção norte e centro-norte a fácies anfibolito médio, na porção sul, ambas de alta pressão.

Palavras-chave: average PT; fácies anfibolito de alta pressão; Grupo Carrancas; química mineral; THERMOCALC.

ABSTRACT - The Luminárias Nappe is a NNE-SSW elongated structure, located in the southern portion of the Neoproterozoic Brasília Orogen, which borders the São Francisco Craton, MG, Brazil. It is composed of metapelite and quartzite from the Carrancas Group. The present work focuses on the metamorphic characterization of the Luminárias Nappe by means of petrography, mineral chemistry and average PT method of THERMOCALC. In the northern portion, the paragenesis is Chl+St+Ky+Rt+Qtz+Ms; in the center-north it is St+Grt+Bt+Rt+Qtz+Ms and in the southern it is Grt+Ky+St+Rt+Qtz+Ms. Retrometamorphic chlorite is observed in the center-north and southern portions, while retrometamorphic biotite is observed in the southern portion. Mineral chemistry data on the rock forming minerals show differences in the composition of minerals from the northern, center-north and southern portion of the Luminárias Nappe. Metamorphic peak conditions (average PT) in the center-northern portion are $570 \pm 67{ }^{\circ} \mathrm{C}$ and $9.4 \pm 1.9 \mathrm{kbar}$, in the southern portion are $609 \pm 63{ }^{\circ} \mathrm{C}$ and $11.4 \pm 3.9 \mathrm{kbar}$. Results indicate the presence of a metamorphic gradient with conditions increasing from lower amphibolite facies in the northern and center-north to medium amphibolite in the southern portion, both at high-pressures.

Keywords: average PT; high-pressure amphibolite facies; Carrancas Group; mineral chemistry; THERMOCALC.

\section{INTRODUÇÃO}

Ao sul da borda meridional do Cráton do São Francisco ocorre o limite entre as faixas Brasília e Ribeira e, na literatura, são apresentadas diferentes interpretações acerca desse limite.
Parte dos autores interpreta que o contato entre essas duas faixas é abrupto (Campos Neto, 2000; Campos Neto et al., 2004), outros consideram que o contato entre as faixas ocorre por zona de 
interferência entre elas (Trouw et al., 2000; Trouw et al., 2013; Peternel et al., 2005).

Localizada no sudeste brasileiro, na região entre Luminárias e São Tomé das Letras, MG, a Nappe de Luminárias se destaca pela ocorrência de conjunto interessante de rochas metamórficas do Grupo Carrancas (Trouw et al., 1980), que é composto por xisto ou filito e quartzito. Na Nappe de Luminárias xisto e filito contêm combinações de quartzo, muscovita, estaurolita, cianita, granada, biotita, cloritoide e rutilo, tornando as rochas interessantes para estudos metamórficos.

Trabalhos sobre o metamorfismo do Grupo Carrancas indicam a presença de gradiente metamórfico variando de fácies xisto verde, na porção norte, para fácies anfibolito na porção sul (Trouw et al., 1980, Trouw et al., 1982;
Ribeiro \& Heilbron, 1982; Peternel et al., 2005), com regimes de pressão próximos ou no início da fácies eclogito (Silva, 2010). Todavia, os dados disponíveis não permitem quantificar as condições de metamorfismo das rochas na Nappe de Luminárias, pois a maior parte dos estudos foi feita na região de Carrancas.

O objetivo do presente trabalho é caracterizar as condições do metamorfismo das rochas da Nappe de Luminárias e usar os resultados para avaliar o contexto tectônico no qual o metamorfismo foi gerado. Para tal, são apresentadas associações minerais representativas dos diferentes estágios do metamorfismo. Dados de química mineral são utilizados para quantificar as condições de pressão e temperatura com o THERMOCALC, utilizando o método de average $P T$.

\section{CONTEXTO GEOLÓGICO DA ÁREA DE ESTUDOS}

A área de estudos se localizada na porção sul do estado de Minas Gerais, abrangendo as proximidades das cidades de Luminárias e São Tomé das Letras. As unidades aflorantes na área pertencem às províncias estruturais do São Francisco, Tocantins e Mantiqueira (Almeida, 1977; Almeida et al., 1981), nas quais ocorrem respectivamente rochas associadas ao Cráton do São Francisco, Faixas Brasília e Ribeira (Figura 1). As rochas que constituem as faixas móveis registram processos metamórficos, magmáticos e sedimentares do Neoproterozoico que atuaram no Ciclo Brasiliano (Brito Neves et al., 1999; Campos Neto, 2000).

A evolução das faixas Brasília e Ribeira pode ser entendida como episódios independentes (Campos Neto, 2000; Campos Neto et al., 2004) ou envolvendo superposição de deformação e de metamorfismo da Faixa Ribeira, mais nova, sobre a Brasília, gerando uma região, ou zona, de interferência (Trouw et al., 2000; Trouw et al., 2013; Peternel et al., 2005). Segundo a proposta de Campos Neto (2000) as rochas da Nappe de Luminárias pertencem ao Sistema de Nappes Carrancas (Figura 1), que possuem afinidades de margem passiva e/ou relacionadas à Placa Sanfranciscana (Campos Neto et al., 2004; Westin \& Campos Neto, 2013; Westin et al., 2016).

Na proposta que postula a existência de zona de interferência entre as faixas Brasília e Ribeira, as rochas da Nappe de Luminárias são associadas às nappes da Megasequência Andrelândia e estão na sua base estrutural (Ribeiro et al., 1995; Trouw et al., 2000; Heilbron et al., 2004 e Heilbron et al., 2008).A Nappe de Luminárias é composta pelas rochas do Grupo Carrancas, definido por Trouw et al. (1980), que o dividiu nas formações Campestre e São Tomé das Letras, constituídas, respectivamente, por filito grafitoso cinza, comumente com granada, estaurolita, cianita e cloritoide, com intercalações de quartzito e quartzito micáceo, algumas vezes com mica verde e intercalado com mica xisto.

Ocorrem também rochas associadas ao embasamento, composto por gnaisse fino bandado, filito, quartzito, gondito, rochas metaultramáficas e ortognaisses (Trouw et al., 1983, 1980 - Figura 2).

Paciullo et al. (2003) reúnem o Grupo Carrancas e o Grupo Andrelândia que, em conjunto, compõem a Megassequência Andrelândia, uma sequência metassedimentar de idade neoproterozoica composta por associações de litofácies distintas e rochas metaígneas associadas, divididas nas unidades $\mathrm{Na}_{1+2}, \mathrm{Na}_{3}$, $\mathrm{Na}_{4}, \mathrm{Na}_{5}$. Segundo esta proposta, as unidades $\mathrm{Na}_{3}$ e $\mathrm{Na}_{4}$ correspondem às formações Campestre e São Tomé das Letras, respectivamente. Westin \& Campos Neto (2013) e Westin et al. (2016) denominam a Unidade $\mathrm{Na}_{1+2}$ de Complexo São Vicente que, segundo os autores, possui idade paleoproterozoica (Figura 1) e, portanto, não podem fazer parte da Megassequência Andrelândia como proposto anteriormente. 


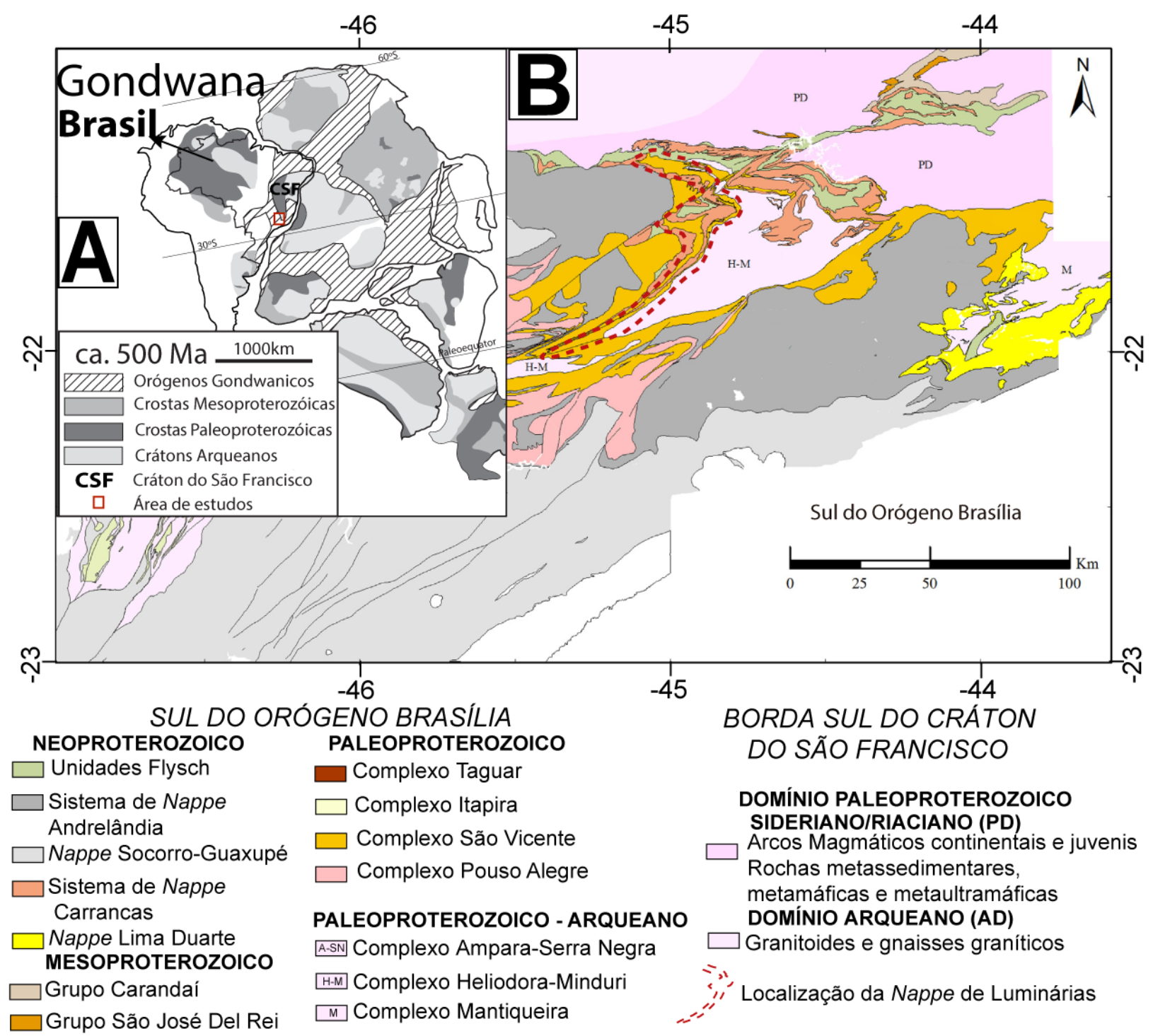

Figura 1 -Mapa da localização da área de estudos. A) Mapa geológico do Gondwana com cerca de 500 Ma., extraído de Spencer et al. (2016). B) Mapa Geológico do Sul do Orógeno Brasília, mostrando a localização da Nappe de Luminárias. Extraído de Westin et al. (2016).

Trouw et al. (1980) e Ribeiro \& Heilbron (1982) descrevem que as condições de metamorfismo das rochas do Grupo Carrancas variam de fácies xisto verde, na porção norte, para fácies anfibolito, na porção sul, ambas com pressões intermediarias, devido à presença de granada e cianita. Nos mapas de distribuição de isógradas metamórficas apresentados por Ribeiro \& Heilbron (1982) e de Trouw et al. (1984), a Nappe de Luminárias é dividida em quatro associações minerais, de norte para sul: granada, granada + estaurolita, granada + estaurolita + cianita, granada + estaurolita + cianita + sillimanita, confirmando o aumento das condições do metamorfismo para sul. Ribeiro \& Heilbron (1982) descrevem a ocorrência de sillimanita no extremo sul da Nappe de Luminárias, a qual é interpretada como resultado do metamorfismo/deformação da Faixa Ribeira, que apresenta regime bárico inferior, sobre a Faixa Brasília.

Mapas posteriores de isógradas metamórficas, como o de Peternel et al. (2005), Reno et al. (2012), Trouw et al. (2013) corroboram os resultados anteriores. Silva (2010) estudou as rochas da Klippe de Carrancas, localizada a nordeste da Nappe de Luminárias, e obteve condições de metamorfismo com condições de pressão mais elevadas que as de metamorfismo barroviano típico, com 12,9 \pm 1 kbar e 608,5 $\pm 19,5{ }^{\circ} \mathrm{C}$. O mapa metamórfico apresentado difere das zonas apresentadas em trabalhos anteriores (Peternel et al., 2005; Reno et al., 2012; Trouw et al., 2013), pois apresenta zonas envolvendo cloritoide + clorita + cianita, cloritoide + clorita + estaurolita \pm granada, clorita + estaurolita + granada, estaurolita + granada + cianita \pm biotita. 


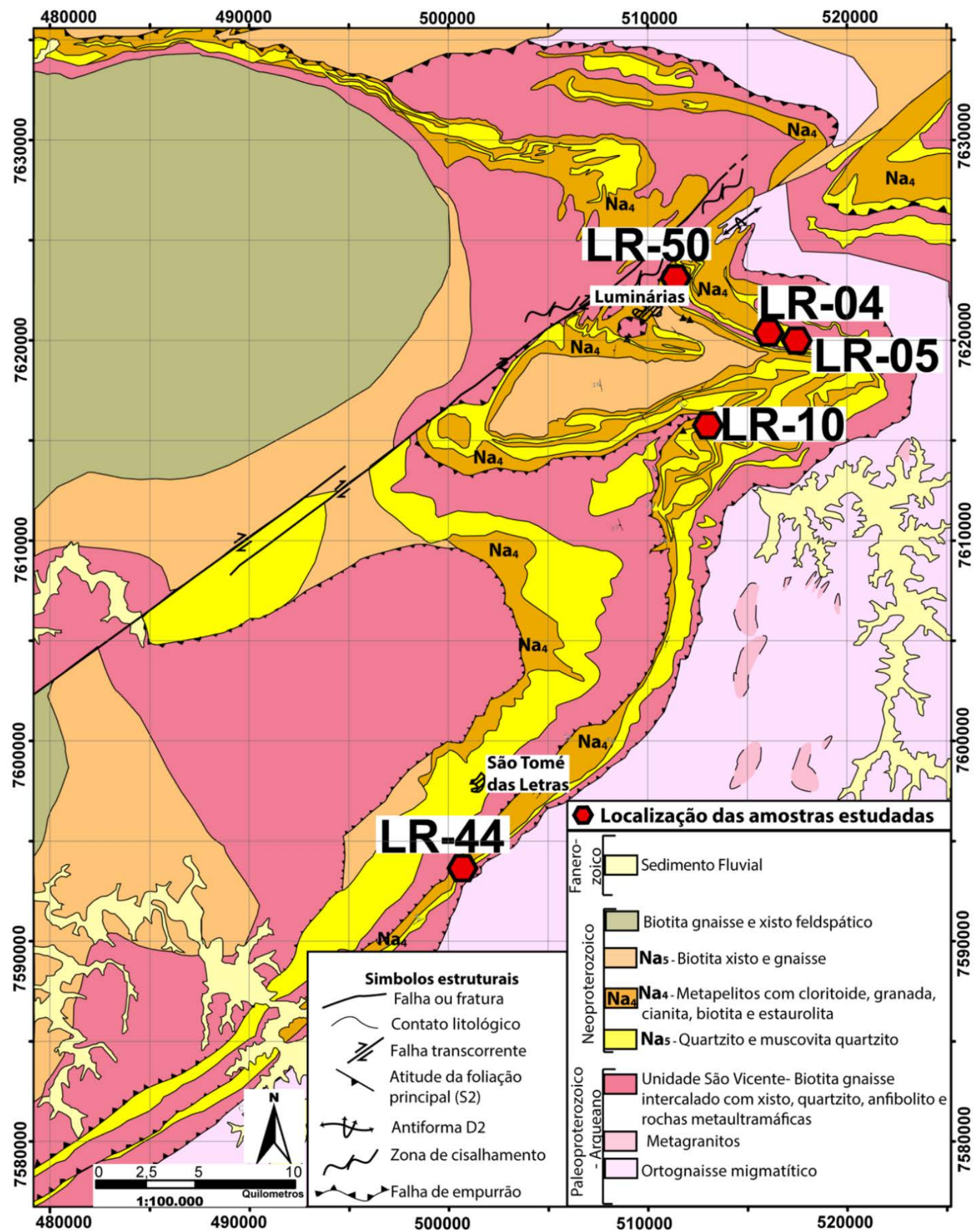

Figura 2 - Mapa Geológico da Nappe de Luminárias e suas adjacências com a localizações das amostras utilizadas nesse trabalho. Foi utilizada a seguinte base geológica: Trouw et al. (2003), Queménéur et al. (2003), Nunes et al. (2008) e Paciullo \& Ribeiro (2008).

\section{MATERIAIS E MÉTODOS}

\section{Trabalho de campo}

Foram realizadas três etapas de trabalho de campo, totalizando doze dias, para reconhecimento das unidades litológicas da área, das relações estruturais entre elas e para coleta de 40 amostras de metapelito para petrografia e análises químicas.

\section{Petrografia}

A petrografia foi realizada em lâminas delgadas visando: 
(i) identificar a ocorrência de minerais índices do metamorfismo;

(ii) identificar texturas que evidenciem processos de metamorfismo;

(iii) identificar as principais reações metamórficas que deram origem as paragêneses;

(iv) estudar a relação entre a deformação e o metamorfismo;

(v) calcular as condições $P-T$ do metamorfismo após as análises de química mineral.

\section{Química mineral}

Os minerais de sete seções delgadas foram analisados na microssonda eletrônica (EPMA). A localização dessas amostras está apresentada na figura 2.

Foram realizadas análises de elementos maiores com a EPMA nos seguintes minerais dos metapelitos: granada, clorita, cloritoide, estaurolita, biotita e muscovita. Para as análises foi utilizado o Laboratório de EPMA do Departamento de Petrologia e Metalogenia (DPM) da Unesp de Rio Claro, equipado com microssonda JEOL JXA8230 Superprobe, com cinco detectores WDS. Para análise dos silicatos, a padronização foi feita em minerais e óxidos, dependendo do elemento a ser analisado.

O tempo de contagem para os elementos maiores foi de 10 segundos no pico e 5 segundos em cada posição do background, inferior e superior.

Utilizou-se aceleração de $15 \mathrm{kV}$ e corrente de $20 \mathrm{nA}$ e feixe focado de 5 micrômetros para as micas e de 1 micra para os outros minerais.

A fórmula química dos minerais foi calculada com o programa $a X$ (url: http://www.esc.cam.ac.uk/research/researchgroups/research-projects/tim-hollands-softwarepages/ax) desenvolvido por Tim Holland.

\section{Termobarometria (average pt)}

Para a termobarometria foi utilizado o programa THERMOCALC (Powell \& Holland, 1988, Holland \& Powell, 1998), versão 6.2 e o método average - $P T$.

Neste trabalho, foi utilizado o banco de dados internamente consistente tc-ds62 atualizado em seis de fevereiro de 2012 (Holland \& Powell, 2011).

\section{PETROGRAFIA}

Por ocorrer ao longo de toda Nappe de Luminárias e por apresentar associações minerais diagnósticas do metamorfismo, foi utilizado o metapelito da unidade $\mathrm{Na}_{4}$ (Paciullo et al., (2003), equivalente à Formação Campestre de Trouw et al., (1980), para a caracterização metamórfica.

Para melhor ilustrar as variações mineralógicas e texturais decorrentes do gradiente metamórfico, compartimentou-se a área em três grandes porções: norte, centronorte e sul.

Em ambas as porções a foliação principal é a $\mathrm{S}_{2}$ que se manifesta como xistosidade ou clivagem de crenulação. A foliação $\mathrm{S}_{1}$ é raramente observada em micrólitons de clivagens de crenulação $S_{2}$ e em regiões de charneira de dobras $\mathrm{D}_{2}$.

\section{Petrografia do norte da Nappe de Luminárias}

Na porção norte da Nappe de Luminárias, a Unidade $\mathrm{Na}_{4}$ é composta por dois litotipos: muscovita xisto porfiroblástico com cloritoide e cianita; e clorita xisto com estaurolita e cianita (Figuras 3A, B, C).

O muscovita xisto porfiroblástico com cloritoide e cianita apresenta textura lepidoblástica, inequigranular porfiroblástica. A matriz é composta por muscovita, clorita, cianita e rutilo, já os porfiroblastos são de cloritoide (Figuras 3A, C).

A granulação da matriz é fina, com dimensão média dos cristais de $0,3 \mathrm{~mm}$, mas os porfiroblastos atingem $4 \mathrm{~mm}$. A xistosidade é marcada pela orientação preferencial dos cristais de muscovita, clorita, ilmenita e rutilo. Frequentemente, a xistosidade $\mathrm{S}_{2}$ está crenulada (Figuras 3A, B).

A rocha é composta por muscovita (80\%) que compõe a matriz, quartzo (5\%) que ocorre como lentes alongadas com extinção ondulante moderada, clorita (5\%), minerais opacos (5\%), rutilo (2\%), cloritoide (3\%) e cianita $(<1 \%)$.

Os porfiroblastos de cloritoide não apresentam sombra de pressão e a trilha de inclusões segue a foliação externa (Figura 3A) indicando que o mineral é pós-cinemático em relação à foliação principal da rocha $\left(\mathrm{S}_{2}\right)$.

A cianita ocorre na matriz, marcando a xistosidade (Figura 3C), e é interpretada como sin-cinemática à foliação $\mathrm{S}_{2}$. 

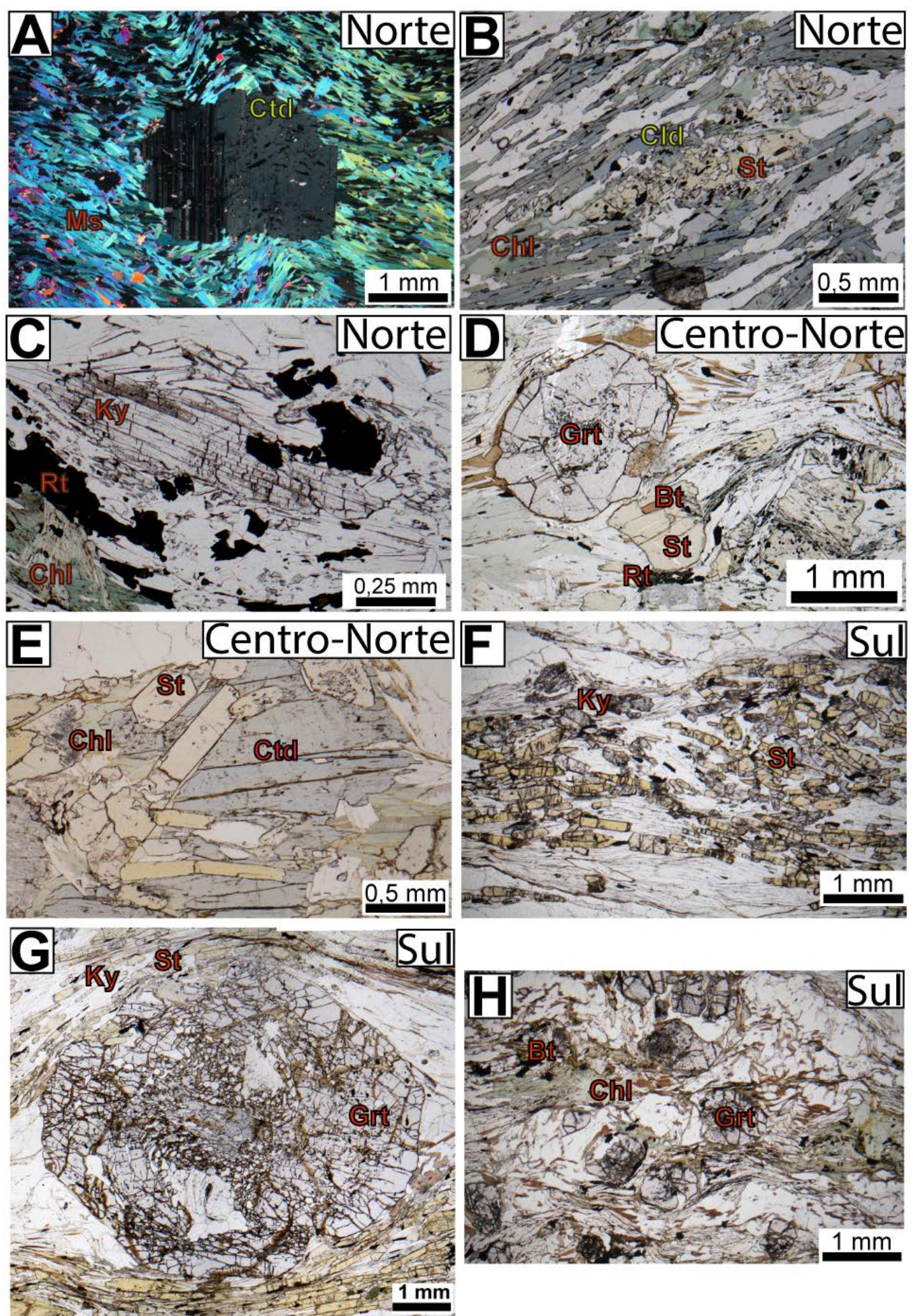

Figura 3 - Fotomicrografias de rochas representativas da Unidade $\mathrm{Na}_{4}$ na Nappe de Luminárias. A) Porfiroblastos póstectônico a $S_{2}$ de cloritoide ao centro do muscovita xisto porfiroblástico com cloritoide e cianita. Matriz com textura lepidoblástica crenulada. Polarizadores cruzados. (Lâmina LR-04 - Centro). B) Porfiblasto de estaurolita do clorita xisto com estaurolita e cianita sendo substituído por cristais de clorita. Polarizadores paralelos. (Lâm. LR-05 - Centro). C) Exemplo de um cristal de cianita do muscovita xisto porfiroblástico com cloritoide e cianita. Na borda inferior esquerda é possível observar cristais de clorita. Polarizadores paralelos. (Lâm. LR-04 - Centro). D) Porfiroblastos de granada e de estaurolita do muscovita xisto porfiroblástico com granada e estaurolita em uma matriz lepidoblástica com muscovita, biotita e clorita. Destaca-se o porfiroblasto de estaurolita com um cristal de biotita incluso. Polarizadores paralelos. (Lâm. LR-10C - Centro-Norte). E) Cloritoide subeudral a anedral do muscovita xisto porfiroblástico com granada e estaurolita englobando cristais euedrais a subedrais de estaurolita. A clorita com cristais anedrais bordeja o cloritoide. Polarizadores paralelos. (Lâm. LR-10E). F) Matriz do estaurolita xisto porfiroblástico com granada e cianita. É possível observar a textura nematoblástica da matriz. Polarizadores paralelos. (Lâm. LR-44C - Sul). G) Porfiroblasto de granada do estaurolita xisto porfiroblástico com granada e cianita. Polarizadores paralelos. (Lâm. LR-44C - Sul). H) Xisto porfiroblástico com granada, mostrando a presença de clorita e biotita tardia. Polarizadores paralelos. (Lâm. LR-44 - Sul). 
O clorita xisto com estaurolita e cianita apresenta textura lepidoblástica, equigranular, de granulação fina. A dimensão média dos cristais é de $0,4 \mathrm{~mm}$.

A foliação $\left(S_{2}\right)$ é definida pela orientação preferencial dos cristais de mica e cristais de quartzo alongados, que forma uma clivagem espaçada de crenulação anastomosada. O domínio de clivagem composto por clorita e o micróliton composto por quartzo.

A rocha é composta por clorita (55\%), quartzo (40\%), que apresenta extinção ondulante intensa a moderada, muscovita (3\%), rutilo (2\%), ilmenita e minerais acessórios, tais como estaurolita (Figura 3B), cianita, que ocorre dispersa, e apatita.

A estaurolita ocorre como cristais com bordas corroídas e que apresentam clorita como a fase que a substituiu (Figura 3B).

\section{Petrografia do centro-norte da Nappe de Luminárias}

$\mathrm{Na}$ porção centro-norte da Nappe de Luminárias, o metapelito da Unidade $\mathrm{Na}_{4}$ é representado por muscovita xisto porfiroblástico com granada e estaurolita. A rocha tem textura lepidoblástica, inequigranular, porfiroblástica (Figura 3 D).

A estrutura é marcada pela orientação dos filossilicatos que definem a clivagem de crenulação $S_{2}$, foliação principal da rocha. A matriz da rocha é composta por muscovita (33 a 54\%), quartzo (20 a 42\%) com extinção ondulante e recristalização dinâmica incipiente, clorita (traço a 23\%), que ocorre tanto na matriz como bordejando os porfiroblastos, biotita (1 a $13 \%$ ), que ocorre inclusa na estaurolita e associada à clorita e a muscovita (Figura $3 \mathrm{D}$ ). Apatita, rutilo e ilmenita ocorrem como minerais acessórios.

Os porfiroblastos são constituídos por granada, estaurolita e, mais raramente, cloritoide. A granada é euédrica a subédrica e poiquiloblástica, com inclusões de quartzo e minerais opacos (Figura $3 \mathrm{D}$ ).

Os cristais de granada apresentam trilhas espiraladas de inclusões que indicam que o mineral está rotacionado em relação à trama da foliação $S_{2}$.

Os seus porfiroblastos apresentam sombra de pressão, evidenciando caráter pré- a sincinemático em relação à foliação principal da rocha $\left(\mathrm{S}_{2}\right)$.
A estaurolita ocorre sob a forma de cristais euédricos na matriz rica em muscovita e também associada à cristais de cloritoide em domínios pouco micáceos.

Os poiquiloblastos de estaurolita contêm inclusões de ilmenita, rutilo e biotita (Figura 3D), as inclusões formam padrões rotacionados que seguem a orientação da foliação $S_{2}$. Devido a esses aspectos a estaurolita é interpretada como sin-cinemática à $\mathrm{S}_{2}$.

Alguns cristais de estaurolita são idioblásticos e estão inclusos no cloritoide, assim eles podem ter cristalizados de forma simultânea, enquanto que a borda da estaurolita que é irregular em contato com a clorita indica que a última é retrometamórfica e que cristalizou as expensas da primeira (Figura 3E).

\section{Petrografia do sul da Nappe de Luminárias}

Na porção sul da Nappe de Luminárias, a Unidade $\mathrm{Na}_{4}$ é representada por estaurolita xisto porfiroblástico com granada e cianita.

A rocha é de textura lepidoblástica, inequigranular e porfiroblástica (Figura 3F). A granulação da matriz é fina, com dimensão média dos cristais de $0,5 \mathrm{~mm}$ e os porfiroblastos de granada alcançam dimensões de até $5 \mathrm{~mm}$ (Figura 3G).

A xistosidade $\left(\mathrm{S}_{2}\right)$ é marcada pela orientação preferencial dos cristais de muscovita e estaurolita (Figura 3F). A matriz é composta por muscovita (45\%), quartzo (35\%), estaurolita $(20 \%)$ e cianita $(<1 \%)$.

Algumas amostras apresentam raros cristais de biotita e clorita na matriz, que ocorrem como cristais anedrais, não apresentam nítida orientação preferencial e são interpretados como tardios, pós-pico metamórfico e póscinemáticos em relação à $\mathrm{S}_{2}$ (Figura $3 \mathrm{H}$ ). Turmalina, rutilo, zircão, apatita, e ilmenita ocorrem como minerais acessórios.

Os poiquiloblastos de granada (15\%) são euedrais a subedrais, com inclusões internas espiraladas de quartzo, estaurolita, ilmenita e rutilo.

As trilhas de inclusões presentes na granada indicam ser pré- a sin-cinemática em relação à foliação principal $\left(\mathrm{S}_{2}\right)$, e que esta foi rotacionada (Figura $3 \mathrm{G}$ ).

A estaurolita é subeudral a euhedral, ocorrendo inclusa na borda dos porfiroblastos de granada e orientada na matriz, levando à interpretação de cristalização pré- a sin- 
cinemática em relação à foliação $S_{2}$.

A cianita não ocorre inclusa na granada e é interpretada como sin-cinemática à foliação, todavia, sua cristalização se deu posteriormente à estaurolita, devido ao fato do mineral estar presente apenas na matriz, associado à estaurolita, mas não ocorrendo incluso na granada.

Os cristais de clorita e biotita não ocorrem orientados e são anedrais (Figura $3 \mathrm{H}$ ), o que indica que são retrometamórficos. A ilmenita forma coroas integrais ou parciais em torno do rutilo.

\section{QUÍMICA MINERAL}

A composição química dos principais minerais das amostras é apresentada a seguir. Análises representativas são apresentadas na Tabela 1.

\section{Granada}

A granada é observada desde o centro-norte até o sul da Nappe de Luminárias e por toda a extensão da estrutura o mineral ocorre como porfiroblastos com variação química entre centro e borda. A fórmula química da granada na porção centro-norte é $\mathrm{Fe}^{2+}{ }_{2,2-2,6} \mathrm{Mn}_{0-0,2} \mathrm{Mg}_{0,2-}$ ${ }_{0,4} \mathrm{Ca}_{0,2-0,5} \mathrm{Ti}_{0-0,3} \mathrm{Fe}^{3+}{ }_{0-0,2} \quad \mathrm{Al}_{1,9-2} \mathrm{Si}_{2,8-3} \mathrm{O}_{12}$ e na porção sul é $\mathrm{Fe}^{2+}{ }_{1,6-2,5} \mathrm{Mn}_{0-0,6} \mathrm{Mg}_{0,1-1,2} \mathrm{Ca}_{0-0,5} \mathrm{Ti}_{0-}$ ${ }_{0,5} \mathrm{Fe}^{3+}{ }_{0-0,8} \mathrm{Al}_{1,8-2} \mathrm{Si}_{2,6-3} \mathrm{O}_{12}$.

$\mathrm{Na}$ porção centro-norte da nappe o membro final principal é almandina. Os teores variando entre $70 \%$ no núcleo e $85 \%$ na borda dos cristais (Figura 4A). O membro final piropo apresenta a mesma tendência de enriquecimento em direção às bordas dos cristais, apresenta teores mínimos de 6,3\% e máximos de 13\% (Figura 4A). Espessartita e grossulária possuem tendência inversa, com empobrecimento em direção às bordas dos cristais. Os teores máximos de espessartita são $7,4 \%$ e os mínimos são 0,6 e os da grossulária variam de $12 \%$ a ausente (Figura 4 A).

No sul da Nappe de Luminárias, a almandina é o membro mais abundante. Os teores variam de $77 \%$ a $67 \%$ no núcleo e de $84 \%$ a $69 \%$ nas bordas (Figura 4C), piropo varia de $11,1 \%$ a $6,3 \%$ no núcleo e de $14,4 \%$ a $6,2 \%$ na borda (Figura 4D).

A espessartita apresenta o padrão inverso, com valores variando entre $21,3 \%$ a $14,3 \%$ no núcleo e 17,0\% a 3,3\% nas bordas (Figura 4F) e a grossulária não apresenta padrão definido, variando entre $3,5 \%$ a $0,9 \%$ (Figura 4E).

\section{Estaurolita}

A estaurolita ocorre desde o norte da Nappe de Luminárias até o sul. Os cristais de estaurolita possuem composição química homogênea. A fórmula química média dos cristais de estaurolita é $\mathrm{Fe}^{2+}{ }_{3,18} \mathrm{Mg}_{0,55}$ $\mathrm{Mn}_{0,01} \mathrm{Ti}_{0,12} \mathrm{Cr}_{0,01} \mathrm{Al}_{17,70} \mathrm{Si}_{7,72} \mathrm{O}_{46,5} \mathrm{H}_{3}$ (Amostra LR-10C - centro-norte - granada xisto porfiroblástico com estaurolita e biotita), $\mathrm{Fe}^{2+}{ }_{3,17} \mathrm{Mg}_{0,52} \mathrm{Ti}_{0,13} \mathrm{Cr}_{0,01} \mathrm{Al}_{17,60} \mathrm{Si}_{7,81} \mathrm{O}_{46,5} \mathrm{H}_{3}$

(Amostra LR-10E - centro-norte - granada xisto porfiroblástico com estaurolita e cloritoide) e $\mathrm{Fe}^{2+}{ }_{3,18} \mathrm{Mg}_{0,59} \mathrm{Mn}_{0,03} \mathrm{Ti}_{0,13} \mathrm{Cr}_{0,01}$ $\mathrm{Al}_{17,59} \mathrm{Si}_{7,77} \mathrm{O}_{46,5} \mathrm{H}_{3}$ (Amostra LR-44C - sul granada-estaurolita xisto com cianita).

A composição química da estaurolita é similar para os três litotipos, salvo algumas diferenças ressaltadas a seguir. $\mathrm{Na}$ porção centro-norte da Nappe Luminárias, os cristais de estaurolita apresentam teores de $\mathrm{Zn}$ mais elevados, entre 0,11 e 0,13 a.p.f.u. na amostra LR-10C, entre 0,05 e 0,09 a.p.f.u. na amostra LR-10E, e entre 0,01 e 0,03 a.p.f.u. na amostra LR-44C. Os teores de Mn são inferiores nas rochas da porção centro-norte quando comparado às do sul da nappe, 0,00 a 0,01 a.p.f.u. na amostra LR-10C, 0,00 a.p.f.u. na amostra LR-10E e 0,02 a 0,03 a.p.f.u. na amostra LR-44C.

\section{Muscovita}

A fórmula média da muscovita na porção centro-norte é $\mathrm{K}_{0,80} \mathrm{Na}_{0,14} \mathrm{Mg}_{0,08} \mathrm{Fe}^{2+}{ }_{0,07} \mathrm{Ti}_{0,02}$ $\mathrm{Al}_{2,78} \mathrm{Si}_{3,09} \mathrm{O}_{10}(\mathrm{OH})_{2}$ (Amostras LR-10C e LR$10 \mathrm{E}$ ) e na porção sul é $\mathrm{K}_{0,81} \mathrm{Na}_{0,12} \mathrm{Mg}_{0,08} \mathrm{Fe}^{2+}{ }_{0,06}$ $\mathrm{Ti}_{0,03} \mathrm{Al}_{2,77} \mathrm{Si}_{3,09} \mathrm{O}_{10}(\mathrm{OH})_{2}$ (Amostras LR-44A e LR-44C). A análise comparativa dos elementos envolvidos nas principais substituições que ocorrem na muscovita mostra que não há variação significativa ao longo da área.

Os teores de Na na porção sul são inferiores, entre 0,10 a 0,14 a.p.f.u., quando comparados aos da porção centro-norte, com valores entre 0,14 a 0,16 a.p.f.u..

Os teores de Mg na porção centro-norte e sul são distintos e o valor médio de $X_{\mathrm{Fe}}$ $\left(X_{\mathrm{Fe}}=\mathrm{Fe} / \mathrm{Fe}+\mathrm{Mg}\right)$ na porção centro-norte é 0,47 e na porção sul 0,44 . 
Tabela 1 - Resumo das análises de química mineral. Foram escolhidos os valores representativos das análises de química mineral realizados. Os valores estão em porcentagem.

\begin{tabular}{|c|c|c|c|c|c|c|c|c|c|c|c|c|c|c|c|c|c|c|c|c|c|c|c|c|c|c|c|c|}
\hline & & \begin{tabular}{l}
$\tilde{m}$ \\
\multirow{2}{*}{}
\end{tabular} & $\begin{array}{l}\bar{\delta}^{\prime} \\
0^{\prime}\end{array}$ & त̂̀ & 8 & $\begin{array}{l}8 \\
\circ\end{array}$ & 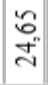 & & & & $\begin{array}{l}\text { to } \\
0^{\circ}\end{array}$ & $\begin{array}{l}\tilde{o}_{0} \\
\delta\end{array}$ & $\begin{array}{l}8 \\
\circ \\
0\end{array}$ & $\begin{array}{l}8 \\
\circ\end{array}$ & $\begin{array}{l}\text { a. } \\
\text { ○. } \\
\infty\end{array}$ & $\stackrel{\text { బ }}{\sim}$ & & & $\begin{array}{l}8 \\
0 \\
0\end{array}$ & 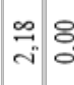 & 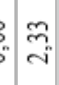 & 8 & & : & & & & \\
\hline & & $\begin{array}{l}\hat{b} \\
\text { aे }\end{array}$ & $\stackrel{\text { '̆ }}{\circ}$ & $\begin{array}{l}m \\
\text { d }\end{array}$ & 总 & $\stackrel{\infty}{\rightarrow}$ & $\begin{array}{l}\text { I } \\
\text { İ }\end{array}$ & ठ̊. & $\stackrel{\circ}{\stackrel{\infty}{\sharp}}$ & 总 & $\begin{array}{l}8 \\
0\end{array}$ & & ৪. & 8 & $\begin{array}{l}\text { aे } \\
\text { s. }\end{array}$ & i & 8 & & & নి & ปั & 8 & 8 & 응 & & & & \\
\hline & & 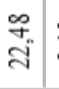 & $\stackrel{\circ}{\circ}$ & ה̃ & $\stackrel{\circ}{\circ}$ & go & $\begin{array}{l}\vec{f} \\
\text { 品 }\end{array}$ & $\begin{array}{l}\text { g. } \\
\text { o. }\end{array}$ & 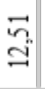 & $\ddot{\circ}$ & 总 & & 足 & 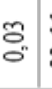 & $\begin{array}{l}: \\
\vdots \\
\vdots \\
\vdots\end{array}$ & g & $\overrightarrow{0}$ & $\vec{S}$ & 呇 & ণ্ & i্ & 8 & $\vec{\circ}$ & $f$ & & & & \\
\hline & & $\stackrel{\text { m. }}{m}$ & $\stackrel{2}{a}$ & $\begin{array}{l}\text { के } \\
\stackrel{\infty}{=}\end{array}$ & 응 & ले & 흠 & $\begin{array}{l}\text { to } \\
0\end{array}$ & $\underset{\infty}{\stackrel{m}{\infty}}$ & : & $\overrightarrow{0}$ & & : & $\overrightarrow{\infty_{\infty}}$ & $\begin{array}{c}5 \\
\text { - } \\
-\end{array}$ & $\stackrel{\text { S }}{\mathrm{S}}$ & $\therefore$ & $E$ & $\frac{ \pm}{\circ}$ & $\stackrel{m}{\rightarrow}$ & $\stackrel{-}{-}$ & 응 & 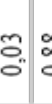 & fo & & & & \\
\hline & & 今్ & $\stackrel{\text { 哭 }}{\rightarrow}$ & $\begin{array}{l}\tilde{a} \\
\Xi\end{array}$ & ㅇ. & 응 & ঐ. & $\overrightarrow{0}_{0}$ & $\begin{array}{l}\overrightarrow{0} \\
\stackrel{0}{-1}\end{array}$ & : & สิ & & $\underset{0}{\exists}$ & $\begin{array}{c}\infty \\
2 \\
\infty \\
\infty\end{array}$ & वे| & $\tilde{i}$ & $\stackrel{0}{\infty}$ & $E$ & : & ন & $\exists$ & : & $\stackrel{\circ}{\circ}$ & F & & & & \\
\hline & & 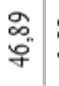 & 合 & $\begin{array}{l}\infty \\
\stackrel{\infty}{2} \\
\tilde{n}^{2}\end{array}$ & 흥 & 8 & $\underset{\Xi}{ \pm}$ & $\begin{array}{l}8 \\
\circ\end{array}$ & $\stackrel{\text { s}}{-}$ & 8 & $\begin{array}{c}\infty \\
\infty_{0}^{\infty} \\
\infty^{\circ}\end{array}$ & & $\frac{a}{0}$ & 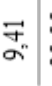 & $\begin{array}{l}n \\
2 \\
2 \\
2\end{array}$ & $\stackrel{g}{\text { di }}$ & $\stackrel{0}{0}$ & $\therefore$ & 8 & $\because: 8$ & $=$ & 8 & $\begin{array}{c}\Rightarrow \\
0 \\
0\end{array}$ & $\because$ & & & & \\
\hline & & $\begin{array}{c}a \\
\Delta^{2} \\
\vec{\gamma}\end{array}$ & ㅇ. & 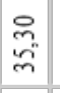 & $\vec{\delta}_{0}$ & 8 & $\stackrel{+}{-}$ & $\begin{array}{l}\overrightarrow{\sigma_{0}} \\
\mathrm{o}^{\circ}\end{array}$ & $\stackrel{ }{=}$ & 8 & $\stackrel{8}{-}$ & & & নू & 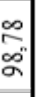 & $\stackrel{m}{m}$ & : & Si & 8 & : & $=$ & : & $\begin{array}{c}9 \\
0\end{array}$ & ô & & & & \\
\hline & & $\begin{array}{l}\text { fa } \\
\underset{\mathbf{d}}{ }\end{array}$ & $\stackrel{\circ}{\circ}$ & 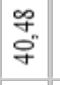 & 응 & స్. & ले & 응 & సે. & : & $\vec{\delta}_{0}$ & & & : & $\begin{array}{l}\text { ह } \\
\text { कू }\end{array}$ & $\underset{m}{m}$ & : & $\hat{\sigma}$ & $\overrightarrow{0}_{0}$ & 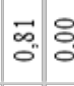 & : స్. & : & $\stackrel{8}{\circ}$ & 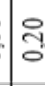 & & & & \\
\hline & & $\begin{array}{l}\infty \\
\stackrel{a}{*}\end{array}$ & $\begin{array}{l}8 \\
\circ\end{array}$ & $\mid \begin{array}{c}\hat{n} \\
\infty \\
\infty \\
m\end{array}$ & 흐. & $\underset{-}{\stackrel{\circ}{-}}$ & 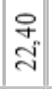 & : & : & 8 & : & & $\begin{array}{l}\vec{\sigma} \\
\sigma_{0}^{\prime}\end{array}$ & : & $\begin{array}{l}\text { 잉 } \\
\text { - }\end{array}$ & $\stackrel{\circ}{\circ}$ & : & 弚 & : & \begin{tabular}{|l|l}
$\overrightarrow{0}$ \\
$\dot{o}^{\prime}$
\end{tabular} & $\Rightarrow$ & 8 & 8 & $\stackrel{\infty}{0}$ & & & & \\
\hline & & $\begin{array}{l}\infty \\
\stackrel{\infty}{\infty} \\
\stackrel{1}{s}\end{array}$ & $\because$ & 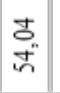 & $\delta_{0}$ & 응 & $\stackrel{\eta}{\exists}$ & $\frac{t}{0}$ & $\exists$ & 응 & $\stackrel{\circ}{\circ}$ & 긍 & & : & $\begin{array}{l}\text { 条 } \\
\text { o. }\end{array}$ & $\stackrel{E}{\approx}$ & $\frac{1}{0}$ & $\begin{array}{l}n \\
\bar{z}\end{array}$ & : & 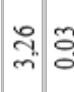 & సू. & 응 & 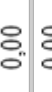 & $\frac{7}{0}$ & & & & \\
\hline & & $\begin{array}{l}\stackrel{a}{a} \\
\vec{i}\end{array}$ & $\begin{array}{l}\tilde{o} \\
\hat{o}\end{array}$ & స్.ి & 总 & 용 & $\begin{array}{c}\mathfrak{q} \\
\tilde{g}\end{array}$ & 응 & 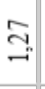 & ㅇ. & $\begin{array}{l}8 \\
\circ\end{array}$ & สे & & : & 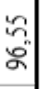 & $\overrightarrow{\vec{\infty}}$ & 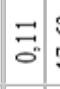 & 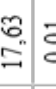 & : 8 & $\stackrel{\circ}{m} \stackrel{\circ}{\circ}$ & : & 응 & $\therefore$ & $\stackrel{ \pm}{0}$ & & & & \\
\hline & & $\begin{array}{c} \pm \\
\text { o. } \\
\text { i. }\end{array}$ & $\underset{0}{F_{0}}$ & 突 & $\stackrel{\check{O}}{\circ}$ & 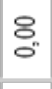 & लొ. & 今. & స్ & $\begin{array}{l}8 \\
\circ\end{array}$ & $\begin{array}{l}8 \\
0^{\prime}\end{array}$ & $\begin{array}{l}\text { ते } \\
\text { के }\end{array}$ & & 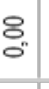 & $\begin{array}{l}\text { 命 } \\
\text { ลे. }\end{array}$ & $\stackrel{\infty}{\sim}$ & o & $\vec{E}$ & : & 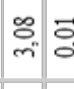 & $\tilde{n}$ & 8 & 8 & $\because$ & & & & \\
\hline & & $\begin{array}{c}\stackrel{8}{0} \\
\text { m. }\end{array}$ & $\bar{\delta}_{\circ}$ & $\begin{array}{l}\overrightarrow{2} \\
\stackrel{8}{\circ}\end{array}$ & $\vec{\delta}_{0}$ & 8 & $\frac{\bar{a}}{\mathrm{~m}}$ & $\begin{array}{l}\curvearrowleft \\
\approx \\
\infty\end{array}$ & $\stackrel{t}{-}$ & 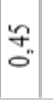 & $\begin{array}{l}8 \\
0\end{array}$ & & & 8 & $\begin{array}{l}\text { o. } \\
\text { ă }\end{array}$ & \%్ & 8 & $\Xi$ & $\begin{array}{l}8 \\
0 \\
0 .\end{array}$ & $\stackrel{2}{\therefore}$ & : స్. & $\begin{array}{l}\overrightarrow{0} \\
0 \\
0\end{array}$ & 8 & ${ }_{0}^{\circ}$ & & $\begin{array}{c}\mathrm{N} \\
0\end{array}$ & & 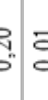 \\
\hline & & 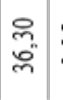 & $\stackrel{\circ}{\circ}$ & $\begin{array}{l}\text { ర్ } \\
\text { ¿ిं }\end{array}$ & $\vec{\circ}$ & $\vec{\exists}$ & $\begin{array}{c}\infty \\
\infty \\
\Omega^{2}\end{array}$ & $\begin{array}{l}\vec{b} \\
\infty\end{array}$ & $\underset{i}{+}$ & \begin{tabular}{ll}
$n$ \\
\hdashline \\
0
\end{tabular} & 응 & & & : & $\begin{array}{l}\text { 이 } \\
\text { a }\end{array}$ & ন্ & 응 & 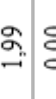 & : & : & సे. & 总 & 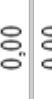 & 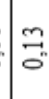 & & : & 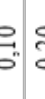 & ca \\
\hline & & $\begin{array}{l}: \\
\stackrel{\circ}{0} \\
\text { r. }\end{array}$ & ठ̊. & : & ㅇ. & $\stackrel{\check{-}}{-}$ & 离 & $\stackrel{\check{s}}{\sim}$ & 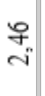 & $\begin{array}{l}\text { iof } \\
0^{\prime \prime}\end{array}$ & 8 & & & : & $\begin{array}{l}\overrightarrow{1} \\
\text { ลू. }\end{array}$ & $\stackrel{g}{\mathscr{g}}$ & 8 & $\stackrel{\circ}{\sim}$ & 8 & 을 & 品 & 总 & 8 & $\because$ & & $\begin{array}{l}\text { ㅇ․ } \\
0 .\end{array}$ & & o \\
\hline & & 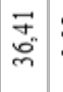 & $\therefore$ & $\begin{array}{l}\tilde{2} \\
\hat{\sim}\end{array}$ & 흥 & 表 & $\frac{a}{\vec{m}}$ & $\begin{array}{l}\stackrel{2}{2} \\
i n\end{array}$ & $\stackrel{\vec{~}}{\mathbf{i}}$ & \begin{tabular}{l}
$\infty$ \\
\hdashline \\
\hdashline
\end{tabular} & 8. & & & : & $\begin{array}{l}\text { 吕 } \\
\text { ă }\end{array}$ & స్ & 8 & $\Xi$ & 8 : & $\stackrel{\infty}{\stackrel{\infty}{c}}$ & $\stackrel{2}{\circ}$ & 总 & 8 & \pm & & है. & & 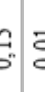 \\
\hline & & $\begin{array}{l}\text { శ్ } \\
\text { - }\end{array}$ & : & $\begin{array}{l}\stackrel{8}{2} \\
\stackrel{8}{2}\end{array}$ & 응 & $\bar{\exists}$ & $\begin{array}{l}0 \\
\\
\end{array}$ & 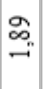 & 음 & స్. & $\tilde{\delta}_{0}^{\circ}$ & & & : & 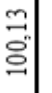 & $\stackrel{\infty}{\stackrel{2}{i}}$ & 응 & 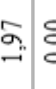 & : & 울 & F & \%. & 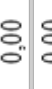 & $\stackrel{2}{\circ}$ & & $\vec{\infty}$ & 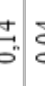 & sa \\
\hline & & $\begin{array}{l}\stackrel{2}{0} \\
\text { 吕 }\end{array}$ & $\stackrel{\Rightarrow}{\circ}$ & $\begin{array}{l}\tilde{\sim} \\
\hat{\sim}\end{array}$ & 8 & హ. & $\begin{array}{c}8 \\
\text { in } \\
\text { m. }\end{array}$ & ה & $\stackrel{\sigma}{-}$ & $\begin{array}{c}\mathscr{\infty} \\
\mathfrak{x}^{-}\end{array}$ & 8 & & & 8 & $\begin{array}{l}n \\
\text { ลू. } \\
\alpha\end{array}$ & 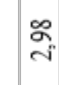 & $\vec{\circ}$ & 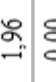 & 8 & $\overrightarrow{\mathrm{N}}$ & 공 & I্ & 8 & $\because$ & & $\begin{array}{c} \pm \\
0 \\
0\end{array}$ & : & 5 \\
\hline & & 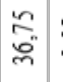 & $\stackrel{g}{\circ}$ & $\begin{array}{l}\text { : } \\
\text { ¿̊. }\end{array}$ & 8 & 응 & $\begin{array}{c}\tilde{\omega} \\
\stackrel{m}{\mathrm{~m}}\end{array}$ & ֶ. & $\stackrel{g}{\Rightarrow}$ & \begin{tabular}{l} 
ț \\
\multirow{*}{*}{}
\end{tabular} & : & & & 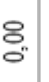 & 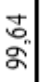 & $\stackrel{\circ}{\sim}$ & $\vec{\circ}$ & $\Xi$ & 8 & $\approx$ & สี & $\frac{9}{0}$ & 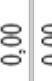 & O & & $\stackrel{0}{\circ}$ & : & 5 \\
\hline & & $\begin{array}{l}: \\
\stackrel{\circ}{0} \\
n^{\circ}\end{array}$ & İ & $\begin{array}{l}\vec{m} \\
\stackrel{8}{2}\end{array}$ & 응 & $\stackrel{ \pm}{\exists}$ & $\mid \begin{array}{c}a \\
0 \\
0\end{array}$ & fo & 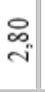 & 욕 & $\stackrel{8}{\circ}$ & & & $\stackrel{\circ}{\circ}$ & $\begin{array}{l}\text { 영 } \\
\text { aे }\end{array}$ & $\stackrel{\infty}{\sim}$ & : & 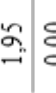 & : & 号 & 宛 & $\stackrel{2}{\circ}$ & 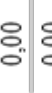 & $\frac{7}{0}$ & & $\begin{array}{c}\tilde{2} \\
0 \\
0\end{array}$ & 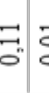 & 5 \\
\hline & & $\begin{array}{l}\circ \\
\text { : } \\
\text { - }\end{array}$ & $\overrightarrow{0_{0}}$ & $\begin{array}{l}\text { aे } \\
\text { ते }\end{array}$ & 今. & 흥 & 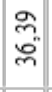 & $\stackrel{\infty}{\infty}$ & a & $\vec{\Xi}$ & $\begin{array}{l}\tilde{\delta} \\
\delta_{0}\end{array}$ & & & : & إڤ & $\stackrel{\infty}{\sim}$ & : & $\stackrel{i}{\circ}$ & : & 足 & $\stackrel{n}{\circ}$ & 志 & $\therefore$ & $\frac{7}{0}$ & & 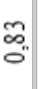 & & 5 \\
\hline 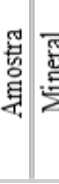 & 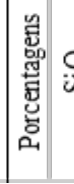 & & 율 & $\begin{array}{l}0^{\prime} \\
\mathbb{u}^{\prime}\end{array}$ & $\overbrace{}^{\infty}$ & $\begin{array}{l}\delta^{\prime} \\
\Phi^{\prime}\end{array}$ & $\begin{array}{l}8 \\
14 \\
14\end{array}$ & 올 & 음 & ᄋ్ల & $\begin{array}{l}\circ \\
\text { 胥 }\end{array}$ & 옥 & & 염 & 丞 & 是 & $\ddot{\mathrm{F}}$ & & 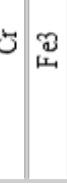 & จ & $\frac{b 0}{2}$ & తే & $\mathrm{z}^{\mathrm{z}}$ & 䜤 & 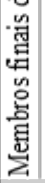 & 韋 & & \\
\hline
\end{tabular}



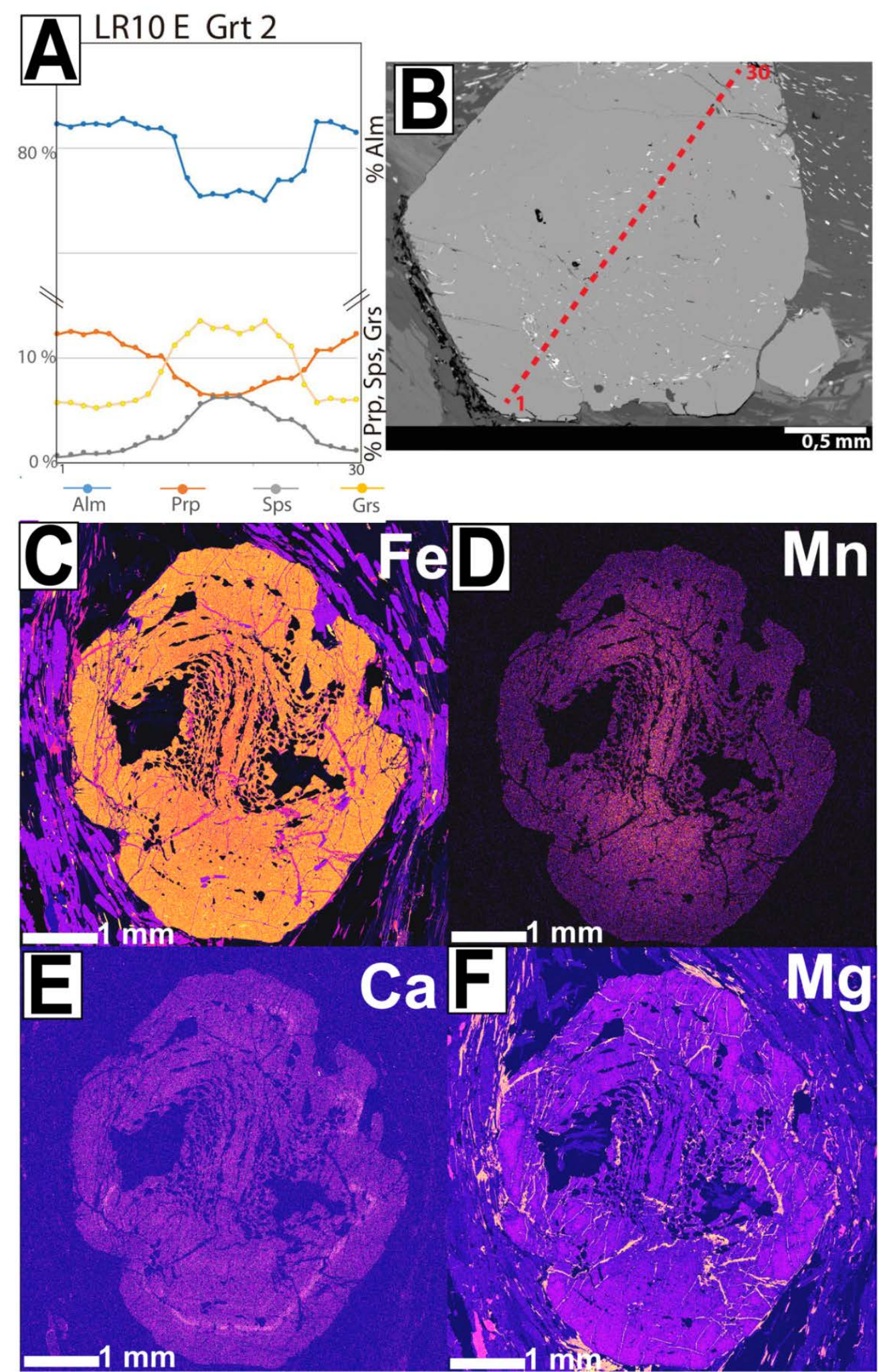

Figura 1 - Análise química mineral da granada. A) Gráfico ilustrando a composição química do perfil de análise química em termos dos membros finais da granada. B) Imagem de elétrons retroespalhados (BSE) do cristal de granada analisado do centro-norte da Nappe de Luminárias (Lâmina LR-10E). C, D, E, F) Mapas composicionais obtidos pela EPMA da granada do sul da Nappe de Luminárias (Lâmina LR-44C). Nessas figuras, é possível observar a variação composicional de $\mathrm{Fe}(\mathbf{C}), \mathrm{Mg}(\mathbf{D}), \mathrm{Ca}(\mathbf{E})$ e $\mathrm{Mg}(\mathbf{F})$ na granada.

\section{Biotita}

A biotita está presente na porção centronorte e sul da Nappe de Luminárias. Duas amostras da porção centro-norte foram analisadas: LR-10C e LR-10E. A fórmula química média da biotita é, respectivamente, $\mathrm{K}_{0,78} \mathrm{Na}_{0,03} \mathrm{Mg}_{1,14} \mathrm{Fe}^{2+}{ }_{1,15} \mathrm{Al}_{1,69} \mathrm{Fe}^{3+}{ }_{0,13} \mathrm{Ti}_{0,08} \mathrm{Si}_{2,7}$ ${ }_{1} \mathrm{O}_{10}(\mathrm{OH})_{2}$ e $\mathrm{K}_{0,75} \mathrm{Na}_{0,03} \mathrm{Mg}_{1,08} \mathrm{Fe}^{2+}{ }_{1,25} \mathrm{Al}_{1,68}$ $\mathrm{Fe}^{3+}{ }_{0,03} \mathrm{Ti}_{0,08} \mathrm{Si}_{2,78} \mathrm{O}_{10}(\mathrm{OH})_{2}$. Na porção sul (LR$\left.44^{\mathrm{A}}\right)$, a fórmula representativa da biotita é 
$\mathrm{K}_{0,86} \mathrm{Na}_{0,03} \mathrm{Mg}_{1,01} \mathrm{Fe}^{2+}{ }_{1,34} \mathrm{Al}_{1,72} \mathrm{Fe}^{3+}{ }_{0,10} \mathrm{Ti}_{0,09} \mathrm{Si}_{2,65}$ $\mathrm{O}_{10}(\mathrm{OH})_{2}$.

Nota-se que os teores de $\mathrm{Fe}^{2+}$ são inferiores para a biotita da porção centro-norte, 1,11 a 1,33 a.p.f.u., em comparação com a biotita da porção sul, 1,26 a 1,38 a.p.f.u.. Os teores de Mg apresentam tendência inversa, com valores superiores na porção centro-norte, 0,94 a 1,16 a.p.f.u., quando comparados à porção sul, 0,99 a 1,07 a.p.f.u. A proporção de $\mathrm{Al}$ é mais elevada na porção sul, 1,70 a 1,74 a.p.f.u. e 1,64 a 1,70 a.p.f.u., no centro-norte. As proporções moleculares de Na variam de 0,02 a 0,04 a.p.f.u. em ambas as porções.

Os teores de Ti são superiores na biotita da porção sul da nappe, 0,08 a 0,12 a.p.f.u. e no centro-norte são entre 0,12 e 0,13 a.p.f.u..

\section{Cloritoide}

O cloritoide ocorre apenas nas porções norte e centro-norte da Nappe de Luminárias. A fórmula representativa dos cristais de cloritoide na porção norte (LR-04) é $\mathrm{Fe}^{2+}{ }_{0,77}$ $\mathrm{Mg}_{0,16} \mathrm{Mn}_{0,05} \mathrm{Al}_{1,95} \mathrm{Fe}^{3+}{ }_{0,07} \mathrm{Si}_{0,99} \mathrm{O}_{5}(\mathrm{OH})_{2}$ e na porção centro-norte (amostra LR-10E) é $\mathrm{Fe}^{2+}{ }_{0,81} \mathrm{Mg}_{0,19} \mathrm{Al}_{1,97} \quad \mathrm{Fe}^{3+}{ }_{0,01} \mathrm{Si}_{1,01} \mathrm{O}_{5}(\mathrm{OH})_{2}$. A composição química do cloritoide é relativamente homogênea. Os cristais da porção norte apresentam valores de $\mathrm{Mg}$ e $\mathrm{Fe}^{2+}$ inferiores quando comparados aos da porção centro-norte. Todavia, $X_{\mathrm{Fe}}$ não se altera significativamente, com 0,82 na porção norte e 0,81 na porção centro-norte da nappe.

Os cristais de cloritoide da porção norte possuem teores mais elevados de $\mathrm{Mn}$ e $\mathrm{Fe}^{3+}$, em relação à porção centro-norte.

\section{Clorita}

A fórmula representativa da clorita na porção norte é $\mathrm{Mg}_{2,02} \mathrm{Fe}^{2+}{ }_{2,43} \mathrm{Mn}_{0,05} \mathrm{Si}_{2,51}$ $\mathrm{Al}_{2,94} \mathrm{Fe}^{3+}{ }_{0,02} \mathrm{Na}_{0,01} \mathrm{O}_{10} \quad(\mathrm{OH})_{16} \quad$ (LR-04), na porção centro-norte é $\mathrm{Mg}_{2,14} \mathrm{Fe}^{2+}{ }_{2,34} \mathrm{Mn}_{0,03}$ $\mathrm{Si}_{2,52} \mathrm{Al}_{2,92} \mathrm{Fe}^{3+}{ }_{0,03} \mathrm{O}_{10}(\mathrm{OH})_{16}$ para a amostra LR10C e $\mathrm{Mg}_{2,15} \mathrm{Fe}^{2+}{ }_{2,10} \mathrm{Si}_{2,78} \mathrm{Al}_{2,69} \mathrm{Na}_{0,01} \mathrm{O}_{10}(\mathrm{OH})_{16}$ na amostra LR-10E.

$\mathrm{Na}$ porção norte, os cristais de clorita apresentam valores mais elevados de $\mathrm{Fe}^{2+}$ e teores intermediários de $\mathrm{Mg}$ quando comparados às demais amostras. Possui valor médio de $X_{\mathrm{Fe}}$ de 0,55 com teores variando de 0,51 a 0,59 . Já no centro-norte da nappe os valores de $\mathrm{Fe}^{2+}$ são intermediários e os valores de $\mathrm{Mg}$ são mais elevados, com o $X_{\mathrm{Fe}}$ médio de 0,51 , com valores variando de 0,59 a 0,48 .

Os teores de $\mathrm{Al}$ contidos na clorita da porção sul são mais baixos que nas demais amostras, com média de 2,77 a.p.f.u., no norte, de 2,69 a.p.f.u., no centro-norte e 2,51 a.p.f.u., no sul.

\section{TERMOBAROMETRIA (THERMOCALC - AVERAGE P-T)}

Foram calculadas as condições de pressão e temperatura do pico do metamorfismo para duas amostras, uma da porção centro-norte, LR-10E, e outra da porção do sul, LR-44C (Figura 5). Não foi possível calcular average PT para amostras da porção norte devido ao fato da estaurolita não estar em equilíbrio textural com os outros minerais (Figura 3B), além disso, o cloritoide analisado nessa porção é pós-cinemático a $\mathrm{S}_{2}$ (Figura 3A), não correspondendo ao pico metamórfico, assim, o programa não consegue definir número mínimo de reações linearmente independentes para os cálculos.

Para a amostra LR-10E a paragênese de pico metamórfico é $\mathrm{Bt}+\mathrm{St}+\mathrm{Grt}+\mathrm{Ms}+\mathrm{Qtz}$ (abreviações segundo Kretz, 1983), considerando a rocha com fase aquosa em excesso, obteve-se $570 \pm 67{ }^{\circ} \mathrm{C}$ e 9,4 $\pm 1,9$ kbar (Figura 5). As condições de $P$ e $T$ calculadas para a amostra LR-44C, cuja paragênese é $\mathrm{Grt}+\mathrm{St}+\mathrm{Ky}+\mathrm{Ms}+\mathrm{Qtz}$, são de $609 \pm 63{ }^{\circ} \mathrm{C}$ e 11,4 $\pm 3,9$ kbar.

\section{DISCUSSÕES}

Com base nos dados obtidos, foi possível caracterizar as condições do pico metamórfico das rochas da Nappe de Luminárias. Na porção norte da Nappe de Luminárias, é observada a paragênese: $\mathrm{St}+\mathrm{Chl}+\mathrm{Ky}+\mathrm{Ms}+\mathrm{Qtz}$, de fácies anfibolito inferior. A paragênese observada na porção centro-norte da Nappe de Luminárias é $\mathrm{Bt}+\mathrm{St}+\mathrm{Grt}+\mathrm{Qtz}+\mathrm{Ms}$, que indica fácies anfibolito médio. Já no sul da Nappe, a paragênese é $\mathrm{Ky}+\mathrm{St}+\mathrm{Grt}+\mathrm{Qtz}+\mathrm{Ms}$, que representa, no local, fácies anfibolito médio de alta pressão, no limite com a fácies eclogito.

No norte da Nappe de Luminárias a ocorrência da paragênese $\mathrm{St}+\mathrm{Chl}+\mathrm{Ky}+\mathrm{Ms}+\mathrm{Qtz}$ indica que foi cruzada a reação metamórfica I (Figura 6):

Equação I

$$
\mathrm{Cld}+\mathrm{Ky} \leftrightarrow \mathrm{St}+\mathrm{Chl}+\mathrm{H}_{2} \mathrm{O}
$$




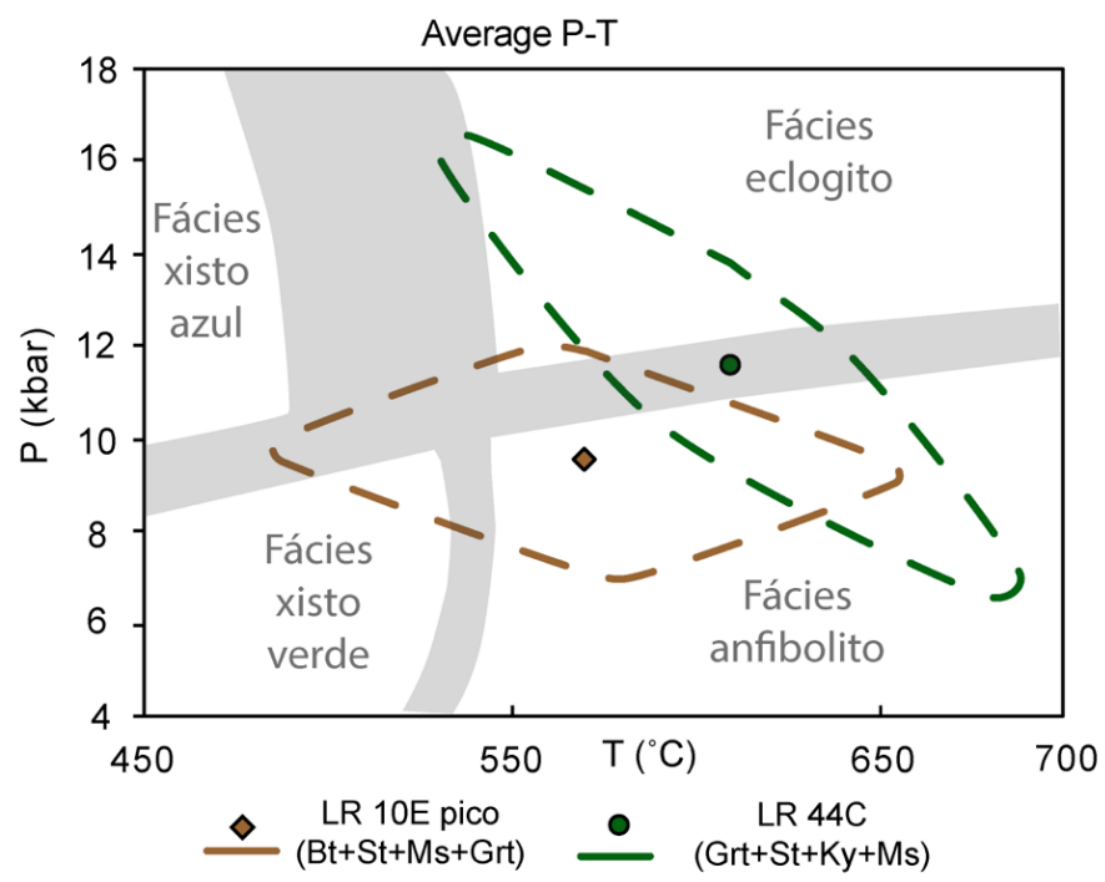

\section{Amostra avT sd(T) avP sd(P) corr

$\begin{array}{llllll}\text { LR 10E } & 570 & 67 & 9,4 & 1,9 & -0,189 \\ \text { LR 44C } & 609 & 63 & 11,4 & 3,9 & -0,892\end{array}$

Figura 5 - Gráfico e tabela mostrando os resultados de average $P T$ das amostras LR-10E (pico= $\left.\mathrm{Bt}+\mathrm{St}+\mathrm{Grt}+\mathrm{Ms}+\mathrm{H}_{2} \mathrm{O}+\mathrm{Qtz}\right)$ e LR-44C $\left(\mathrm{Grt}+\mathrm{St}+\mathrm{Ky}+\mathrm{Ms}+\mathrm{H}_{2} \mathrm{O}+\mathrm{Qtz}\right)$. Limite das fácies metamórficas extraído de Winter, 2010. Av = média, $\mathrm{T}=$ temperatura, $\mathrm{P}=$ pressão, $\mathrm{sd}=$ desvio padrão e corr $=$ correlação, temperatura em ${ }^{\circ} \mathrm{C}$ e pressão em kbar. Abreviações segundo Kretz, 1983.

Na porção centro-norte ocorre a formação da biotita através da equação II (figura 6).

Equação II

$$
\mathrm{Grt}+\mathrm{Chl}+\mathrm{Ms} \leftrightarrow \mathrm{St}+\mathrm{Bt}+\mathrm{Qtz}+\mathrm{H}_{2} \mathrm{O}[I I]
$$

Na porção sul ocorre a estabilização de cianita na paragênese mineral pela reação III, via consumo de clorita (Figura 6).

Equação III

$$
S t+C h l+Q t z \leftrightarrow K y+G r t+H_{2} O[I I I]
$$

Além das paragêneses metamórficas descritas, foram observadas associações minerais do retrometamorfismo.

Na porção norte da Nappe de Luminárias, a clorita ocorre nas bordas corroídas da estaurolita (Figura 3B).

Na porção centro-norte da Nappe é observada clorita retrometamórfica na matriz e bordejando cristais de cloritoide e estaurolita (Figura 3E).

Na porção sul, ocorrem cristais anedrais de clorita e biotita, com disposição aleatória na matriz, textura essa considerada retrometamórfica (Figura 3H).

Comparando as paragêneses descritas na
Nappe de Luminárias por Trouw et al. (1980), Ribeiro \& Heilbron (1982), Peternel et al. (2005), Reno et al. (2012) e Trouw et al. (2013), com as paragêneses descritas no presente trabalho, nota-se que o início da ocorrência da granada e a paragênese $\mathrm{Grt}+\mathrm{St}+\mathrm{Ky}$ foram observadas mais ao sul do que nos mapas descritos na literatura.

Além disso, não foi observada a presença de sillimanita na porção sul da nappe, como alguns desses trabalhos apontam. Os dados do presente trabalho confirmam a presença do gradiente metamórfico, obliquo à direção dos contatos geológicos, mostrando que as condições de pressão e de temperatura aumentam para sul.

Não é possível observar variação nas condições metamórficas da base para o topo estrutural da unidade $\mathrm{Na}_{4}$. Nota-se que o presente estudo não abrange o extremo norte da Nappe de Luminárias, onde segundo a literatura (Trouw et al., 1980, Ribeiro \& Heilbron, 1982, Peternel et al., 2005, Reno et al., 2012 e Trouw et al., 2013) ocorrem rochas de fácies xisto verde. 


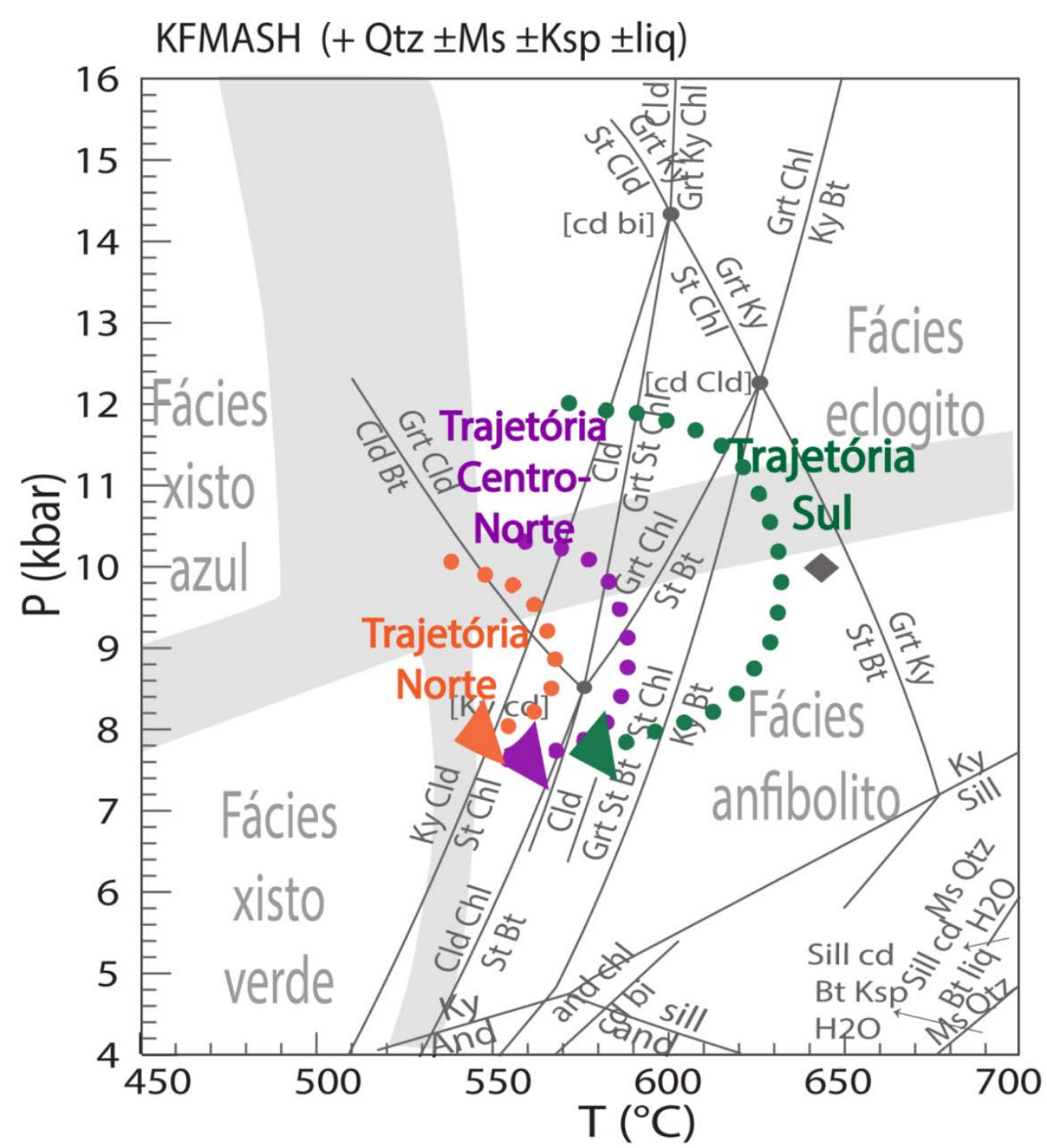

Figura 6: Grade petrogenética no sistema KFMASH, extraída de White et al. (2014), contendo as trajetórias metamórficas traçadas para as porções norte, centro-norte e sul da Nappe de Luminárias. O limite das fácies metamórficas foi extraído de Winter, 2010. As trajetórias foram traçadas utilizando as reações metamórficas observadas nas diferentes associações minerais.

Assim como as diferentes paragêneses observadas ao longo da Nappe de Luminárias, também foram caracterizadas algumas distinções na química dos principais minerais, as quais ilustram que as condições de metamorfismo nas porções norte, centro-norte e sul da Nappe de Luminárias foram diferentes, tais como os teores de Fe, Mn e Mg na granada; de Zn e Mn na estaurolita; de $\mathrm{Na}, X_{\mathrm{Fe}}$ na muscovita; de $\mathrm{Fe}^{3+}, \mathrm{Mg}$, Al e $\mathrm{Ti}$ a biotita; de $\mathrm{Mg}, \mathrm{Fe}^{2+}, \mathrm{Fe}^{3+}$ e $\mathrm{Mn}$ no cloritoide e de $\mathrm{Fe}^{2+}$ e $\mathrm{Al}$ na clorita. Além disso, o zoneamento químico nos porfiroblastos de granada, que ocorrem em toda a extensão da nappe, indica que a sua cristalização registrou aumento de temperatura durante o metamorfismo progressivo, já que há aumento de $\mathrm{Mg}$ para as bordas dos cristais e diminuição de Mn. Um dado interessante confirma, que confirma o caráter de alta pressão do metamorfismo das rochas da nappe, é a proporção relativamente alta de $\mathrm{Na}$ na muscovita, o que gera molécula de paragonita de forma significativa na química do mineral.

A termobarometria usando o método average $P T$ do THERMOCALC se mostrou eficiente na caracterização das condições do pico metamórfico das rochas da Nappe de Luminárias. As condições metamórficas obtidas pelo método confirmam o gradiente metamórfico, com aumento de temperatura e pressão de norte para o sul.

Apesar do método de average $P T$ se mostrar útil, os desvios padrões obtidos são elevados e, deste modo, as diferenças de pressão entre os resultados das porções norte e sul devem ser avaliadas com cuidado. 
A dificuldade em se obter resultados mais precisos de pressão está vinculada à ausência de plagioclásio no xisto, que quando conjugado à granada gera um dos barômetros mais precisos para metapelito.

Trouw et al. (1982), Trouw et al. (1983), Ribeiro et al. (1995) descrevem que as condições de metamorfismo da região é do tipo barroviano, de pressão intermediária a alta. Dados apresentados por Silva (2010) para rochas da Klippe de Carrancas indicam condições de pico em pressões mais elevadas do que as do metamorfismo barroviano típico. Os resultados obtidos no presente trabalho também indicam condições de pressão mais elevadas, que alcançam $11,8 \pm 2,8$ kbar com $608 \pm 47{ }^{\circ} \mathrm{C}$ e na porção sul da Nappe de Luminárias. Isto implica que as rochas metassedimentares estudadas alcançaram condições profundas da crosta, no limite entre as fácies anfibolito e eclogito, como evidenciado anteriormente por Silva (2010) para as rochas da região de Carrancas.

Além disso, as condições aqui calculadas estão em acordo com os resultados obtidos pelo autor e implicam em subducção de rochas da crosta continental. As paragêneses constituídas por cianita + estaurolita + granada \pm clorita \pm cloritoide são boas marcadoras de temperatura, mas não de pressão.

No entanto, pelitos afetados por metamorfismo de alta pressão são carac-terizados exatamente por essas paragêneses, como discutido por Koons \& Thompson (1985) e que podem alcançar pressões de até 16 kbar.

\section{CONCLUSÕES}

Os dados obtidos no presente trabalho permitem concluir que:

- A área é marcada pela ocorrência de gradiente metamórfico com condições que variam de fácies anfibolito inferior, no norte, para fácies anfibolito médio de alta pressão, próximo das condições da fácies eclogito, no sul. A paragênese observada na porção centro-norte da Nappe de Luminárias é clorita + estaurolita + cianita + muscovita + quartzo, na porção centronorte é biotita + estaurolita + granada + muscovita + quartzo e no sul é granada + estaurolita + cianita + muscovita + quartzo.

- O gradiente metamórfico é oblíquo aos contatos das unidades.

- As trajetórias metamórficas registradas nas rochas da Nappe de Luminárias são horárias, registrando aquecimento seguido de uma forte descompressão e resfriamento (Figura 6).

- As condições de pressão registradas nas rochas estudadas são superiores àquelas sugeridas na literatura para a área de estudos, e estão em acordo com os cálculos apresentados por Silva
(2010). Estas condições indicam que as rochas se formaram em condições mais profundas, implicando em rápida subducção e exumação de rochas da crosta continental, de modo que as rochas gravam paragêneses de temperaturas medianas e de alta pressão, mas não tiveram tempo para se equilibrar com temperaturas muito altas.

- A caracterização metamórfica usando petrografia, química mineral e termobarometria pelo método average $P T$ se mostrou eficiente na caracterização metamórfica das rochas da área de estudo.

Sugere-se para os próximos trabalhos na área o refinamento da termobarometria com o uso de geotermobarometros mais precisos, como os de elementos traço em minerais, i.e. $\mathrm{Zr}$ em rutilo (Zack et al., 2004; Tomkins et al., 2007) e Ti em quartzo (Wark \& Watson, 2006), a confecção de pseudosseções com isopletas de composição mineral, para a modelagem metamórfica, e a datação do pico do metamorfismo usando o método U-(Th)-Pb em monazita e rutilo.

\section{AGRADECIMENTOS}

À Coordenadoria de Aperfeiçoamento de Pessoal de Nível Superior (Capes) e à Fundação de Amparo a Pesquisa do Estado de São Paulo (FAPESP) (projetos 2015/07750-5, 2015/05230-0, 2013/04007-0) pelo apoio financeiro. Os autores agradecem à Professora Dra. Carla Porcher pelas correções e sugestões que possibilitaram a melhoria do artigo.

\section{REFERÊNCIAS}

ALMEIDA, F. F. M. O Cráton do São Francisco.

Revista Brasileira de Geociências, v. 7, p. 349-364, 1977.
ALMEIDA, F. F. M.; HASUI, Y.; BRITO NEVES, B. B. DE; FUCK, R. A. Brazilian Structural Provinces: An Introduction. Earth 
Science Reviews, v. 17, p. 1-29, 1981.

BRITO NEVES, B. B. de; CAMPOS NETO, M. D.; FUCK, R. A. From Rodinia to Western Gondwana: as Aproach to the Brasiliano-Pan African Cycle and orogenic collage. EpisodesNewsmagazine of International Union of Geological Science, v. 22, n. 155-166, 1999.

CAMPOS NETO, M. D. C. \& CABY, R. Neoproterozoic high-pressure metamorphism and tectonic constraint from the nappe system south of the Sao Francisco Craton, southeast Brazil. Precambrian Research, v. 97, n. 1-2, p. 3-26, 1999.

CAMPOS NETO, M. D. C. Orogenic Systems from Southwestern Gondwana: An Approach to Brasiliano-Pan African Cycle and Orogenic Collage in Southeastern Brazil. In: CORDANI, U. G. et al. (Eds). Tectonic Evolution of South America. Rio de Janeiro: Companhia de Pesquisa de Recursos Minerais, p.335-365, 2000.

CAMPOS NETO, M. D. C.; BASEI, M. A. S.; VLACH, S. R. F.; CABY, R.; SZABÓ, G. A. J. Migração de Orógenos e Superposição de Orogêneses: Um Esboço da Colagem Brasiliana no Sul do Cráton do São Francisco, SE - Brasil. Geologia USP - Série Científica, v. 4, n. 1, p. 13-40, 2004.

HEILBRON, M.; PEDROSA-SOARES, A. C.; CAMPOS NETO, M. D. C.; SILVA, L. D.; TROUW, R. A. J.; JANASI, V. D. A. Província Mantiqueira. In: Geologia do Continente sulamericano: evolução da obra de Fernando Flávio Marques de Almeida. São Paulo: Editora Beca, p. 203-235, 2004.

HEILBRON, M.; VALERIANO, C.M.; TASSINARI, C.C.G.; ALMEIDA, J.; TUPINAMBÁ, M.; SIGA, O.; TROUW, R. Correlation of Neoproterozoic terrane between the Ribeira Belt, SE Brazil and its African countepart: comparative tectonic evolution and open questions. Geological Society, London, Special Publications, v. 294, p. 211-237, 2008.

HOLLAND, T. \& POWELL, R. An internally consistent thermodynamic data set for phases of petrological interest. Journal of metamorphic Geology, v. 16, n. 3, p. 309-343, 1998.

HOLLAND, T. J. B. \& POWELL, R. An improved and extended internally consistent thermodynamic dataset for phases of petrological interest, involving a new equation of state for solids. Journal of Metamorphic Geology, v. 29, n. 3, p. 333-383, 2011.
KOONS, P.O. \& THOMPSON, A.B. Non-mafic rocks in the greenschist, blueschist and eclogite facies. Chemical Geology, v.50, n.1-3, p.3-30, 1985.

KRETZ, R. Symbols for rock-forming minerals. American Mineralogist, v. 68, p. 277-279, 1983.

NUNES, R.P. M.; TROUW, R.A.J.; CASTRO, E.O. Mapa Geológico - Folha Varginha (1:100.000). In: Programa Geologia do Brasil. Levantamentos Geológicos básicos. Contrato Serviço Geológico do Brasil Universidade Federal do Rio de Janeiro, 2008.

PACIULLO, F. V. P. \& RIBEIRO, A. Mapa Geológico - Folha Nepomuceno (1:100.000). In: Programa Geologia do Brasil. Levantamentos Geológicos básicos. Serviço Geológico do Brasil - Universidade Federal do Rio de Janeiro, 2008.

PACIULLO, FABIO V.P; TROUW, R.A.J.; RIBEIRO, A.; SIMÕES, L.A.; LOPES, M. Geologia da Folha Andrelândia 1:100.000. Geologia e recursos minerais do sudeste mineiro. Projeto Sul de Minas-Etapa I, p.84119, 2003.

PETERNEL, R.; TROUW, R. A. J.; SCHMITT, R. D. S. Interferência Entre Duas Faixas Móveis Neoproterozoicas: O Caso Das Faixas Brasília e Ribeira No Sudeste Do Brasil. Brazilian Journal of Geology, v. 35, n. 3, p. 297-310, 2005.

POWELL, R. \& HOLLAND, T. J. B. An internally consistent dataset with uncertainties and correlations: 3. Applications to geobarometry, worked examples and a computer program. Journal of metamorphic Geology, v. 6, n. 2, p. 173-204, 1988.

QUÉMÉNEUR, J. J. G.; RIBEIRO, A., PACIULLO, F. V. P., HEILBRON, M.; TROUW, R. A. J.; VALENÇA, J. G.; NOCE, C. M. Mapa geológico da Folha Lavras. Projeto Sul de Minas: mapa (1: 100.000) e relatório. Codemig-Secretaria de Estado de Desenvolvimento Econômico de Minas Gerais. 822p, 2003.

RENO, B. L; PICCOLI, P. M.; BROWN, M; TROUW, R. A. J. In situ monazite (U-Th)-Pb ages from the Southern Brasília Belt, Brazil: Constraints on the high-temperature retrograde evolution of HP granulites. Journal of Metamorphic Geology, v. 30, n. 1, p. 81-112, 2012. 
RIBEIRO, A. \& HEILBRON, M. Estratigrafia e Metamorfismo dos Grupos Carrancas e Andrelândia, Sul de Minas Gerais. In: CONGRESSO BRASILEIRO DE GEOLOGIA, 32, 1982, Salvador. Anais... Salvador: Sociedade Brasileira de Geologia, p. 177-186, 1982.

RIBEIRO, A.; TROUW, R. A., ANDREIS, R. R., PACIULlO, F. V.; VALENÇA, J. G. Evolução das Bacias Proterozoicas e o TermoTectonismo Brasiliano na Margem Sul do Cráton do São Francisco. Revista Brasileira de Geociências, v. 25, n. 4, p. 235-248, 1995. SILVA, M. P. Modelamento Metamórfico de Rocas das Fácies Xisto-Verde e Anfibolito com o Uso de Pseudosseções: Exemplo das Rochas da Klippe Carrancas, Sul de Minas Gerais. São Paulo, 2010. 184p. Dissertação (Mestrado), Instituto de Geociências, Universidade de São Paulo.

SPENCER, C. J.; HAWKESWORTH, C.; CAWOOD, P. A.; DHUIME, B. Not all supercontinents are created equal: Gondwanarodinia case study. Geology, v. 41, n. 7, p. 795-798, 2013.

TOMKINS, H. S.; POWELL, R.; ELLIS, D. J. The pressure dependence of the zirconium-inrutile thermometer. Journal of Metamorphic Geology, v. 25, n. 6, p. 703-713, 2007.

TROUW, R. A.; RIBEIRO, A.; PACIULLO, F. V. P. Evolução Estrutural e Metamórfica de uma área a SE de Lavras - Minas Gerias. In: CONGRESSO BRASILEIRO DE GEOLOGIA, 31, 1980, Balneário de Camboriú. Camboriú. Anais... Balneário de Camboriú: Sociedade Brasileira de Geologia, p. 2273-2284, 1980.

TROUW, R. A. J.; PACIULLO, F. V. P.; CHRISPIM, S. J.; DAYAN, H, H. Análise de Deformação numa Área a SE de Lavras Minas Gerais. In: CONGRESSO BRASILEIRO DE GEOLOGIA, 32, 1982, Salvador. Anais... Salvador: Sociedade Brasileira de Geologia, p. 187-198, 1982.

TROUW, R. A. J.; RIBEIRO, A.; PACIULLO, F. V. Geologia Estrutural do Grupos São João del Rei, Carrancas e Andrelândia, Sul de Minas Gerais. Anais da Academia brasileira de Ciências, v. 55, n. 1, p. 71-87, 1983.

TROUW, R.A.; HELBRON, M.; RIBEIRO, A.; PACIULLO, F.V.P.; VALERIANO, C.M., ALMEIDA, J.C.; TUPINAMBÁ, M.;
ANDREIS, R. R. The Central Segment of the Ribeira Belt. In: CORDANI, U. G. (Eds), Tectonic Evolution of South America. Rio de Janeiro: 31st International Geological Congress, p. 287-310, 2000.

TROUW, R. A. J.; PACIULLO, F. V. P.; RIBEIRO, A.; BITTAR, S.; ALMEIDA, J. C. H. Mapa Geológico da Folha Caxambu. Projeto Sul de Minas: mapa (1: 100.000) e relatório. Comig-Secretaria de Estado de Desenvolvimento Econômico de Minas Gerais. p. 822, 2003.

TROUW, R.A.J.; PETERNEL, R.; RIBEIRO, A.; HEILBRON, M.; VINAGRE, R.; DUFFLES, P.; TROUW, C.A new interpretation for the interference zone between the southern Brasília belt and the central Ribeira belt, SE Brazil. Journal of South American Earth Sciences, v. 48, p. 43-57, 2013.

WARK, D. A. \& WATSON, E. B. Titanic: a titanium-in-quartz geothermometer. Contributions to Mineralogy and Petrology, v. 152, p. 743-754, 2006.

WESTIN, A. \& CAMPOS NETO, M. D. C. Provenance and tectonic setting of the external nappe of the Southern Brasília Orogen. Journal of South American Earth Sciences, v. 48, p. 220-239, 2013.

WESTIN, A.; CAMPOS NETO, M.C.; HAWKESWORTH, C.J., CAWOOD, P.A.; DHUIME, B., DELAVAULT, H. A paleoproterozoic intra-arc basin associated with a juvenile source in the Southern Brasília Orogen: Application of $\mathrm{U}-\mathrm{Pb}$ and $\mathrm{Hf}-\mathrm{Nd}$ isotopic analyses to provenance studies of complex areas. Precambrian Research, v.276, p.178-193, 2016. WHITE, R. W.; POWELL, R.; HOLLAND, T. J. B.; JOHNSON, T. E.; GREEN, E. C. R. New mineral activity-composition relations for thermodynamic calculations in metapelitic systems. Journal of Metamorphic Geology, v. 32, n. 3, p. 261-286, 2014.

ZACK, T.; MORAES, R.; KRONZ, A. Temperature dependence of $\mathrm{Zr}$ in rutile: Empirical calibration of a rutile thermometer. Contributions to Mineralogy and Petrology, v. 148, n. 4, p. 471-488, 2004.

Submetido em 25 de janeiro de 2017 Aceito em 27 de setembro de 2017 